\title{
Ensaios Acelerados Empregados na Indução da Corrosão por Cloretos - Análise a Partir de Concretos com a Incorporação de Resíduos de Tijolos Moídos
}

\author{
Pablo Ramon Rodrigues Ferreira \\ Gibson Rocha Meira \\ Valdith Lopes Jerônimo
}

\section{Cenário dos Ensaios Acelerados Empregados na Indução da Corrosão por Cloretos no Concreto}

Diversas metodologias experimentais têm sido utilizadas para simular, de forma acelerada, a ação dos cloretos sobre o concreto armado. Essas metodologias diferem não só quanto à forma de introdução dos cloretos na matriz estudada, mas também em relação às diferentes técnicas de monitoramento e aos critérios de avaliação do início do processo de corrosão nas armaduras. Aliado a esses aspectos, cada material apresenta respostas diferenciadas em função da composição que apresenta, da idade, do ambiente de exposição, do modo de confecção e de aplicação (TREJO et al., 2009).

Parte desses estudos foi realizada dispondo a armadura em solução alcalina, de modo a simular o meio ao qual a armadura está submetida no concreto. Logo, esse tipo de meio pode ter facilmente o $\mathrm{pH}$ e a concentração de cloretos alteradas com precisão, a critério do pesquisador (TREJO et al., 2009). Contudo, o estudo da corrosão por cloretos em soluçóes tem a limitação de náo permitir a avaliação do transporte de cloretos em uma matriz cimentícia e náo representar com fidelidade as condiçóes de interaçáo matriz - armadura.

Quando se utiliza pasta de cimento, argamassa ou concreto, a penetração de cloretos em corpos de prova se torna mais demorada e a quantificação da 
concentração de cloretos presente na superfície do aço, mais difícil e trabalhosa (ANGST et al., 2009). No entanto, esses estudos tentam acelerar o transporte de cloretos, a fim de se obter resultados mais rápidos em comparação com os métodos de exposição natural, que, embora representem condição semelhante ao caso de estruturas reais, são inviáveis para uso regular, em função do tempo que demandam.

$\mathrm{Na}$ literatura, registram-se diversos métodos de ensaio para indução do transporte e da corrosão por cloretos. Todos esses métodos de ensaio acelerado se baseiam em variaçóes dos mecanismos de transporte dos íons cloretos no interior do concreto, com exceção da adição de cloretos à massa de concreto fresco e das soluçôes simuladoras da fase líquida do concreto (ANGST et al., 2009). As Figuras 1 e 2 mostram as formas como os cloretos têm sido incorporados em ensaios acelerados de corrosão, considerando os cenários internacional e nacional, respectivamente. Nesse levantamento, foram consideradas 39 publicaçóes internacionais e 16 publicaçóes nacionais.

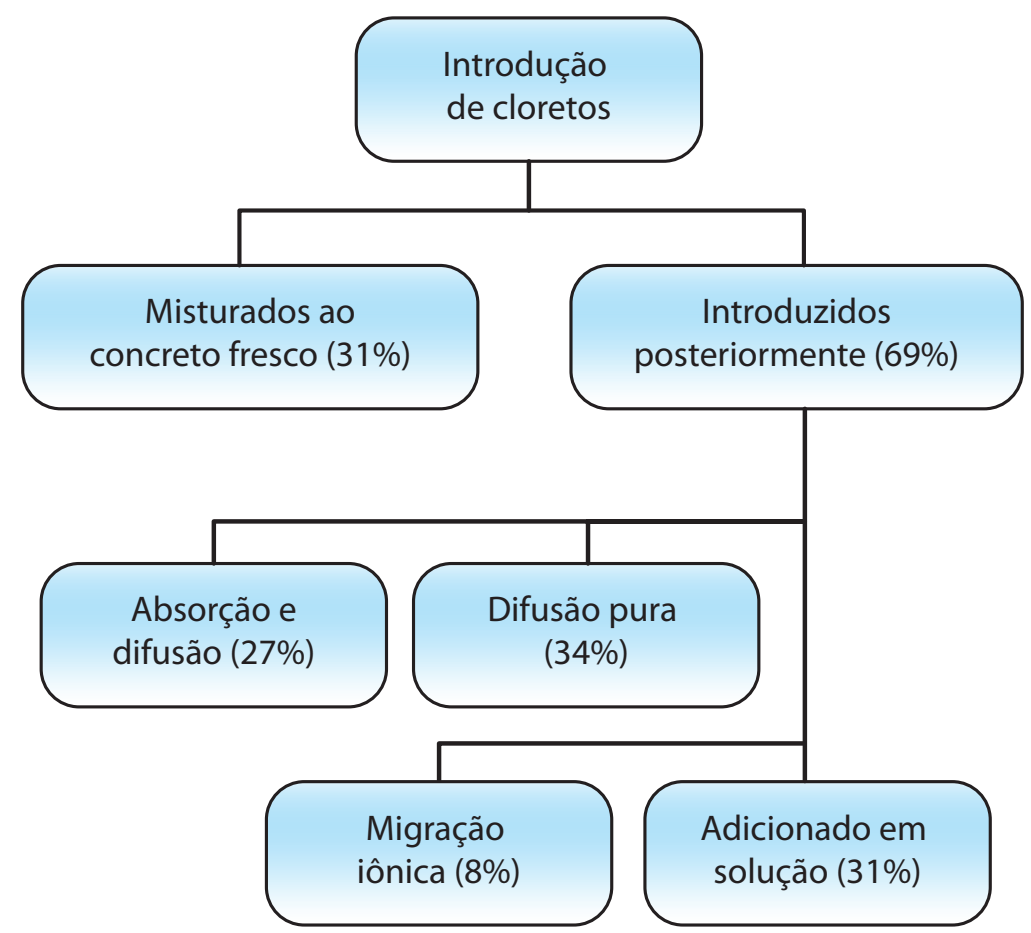

Figura 1. Formas de introdução de cloretos em ensaios acelerados de corrosão - Cenário internacional. Fonte: Angst e Vennesland (2009). 


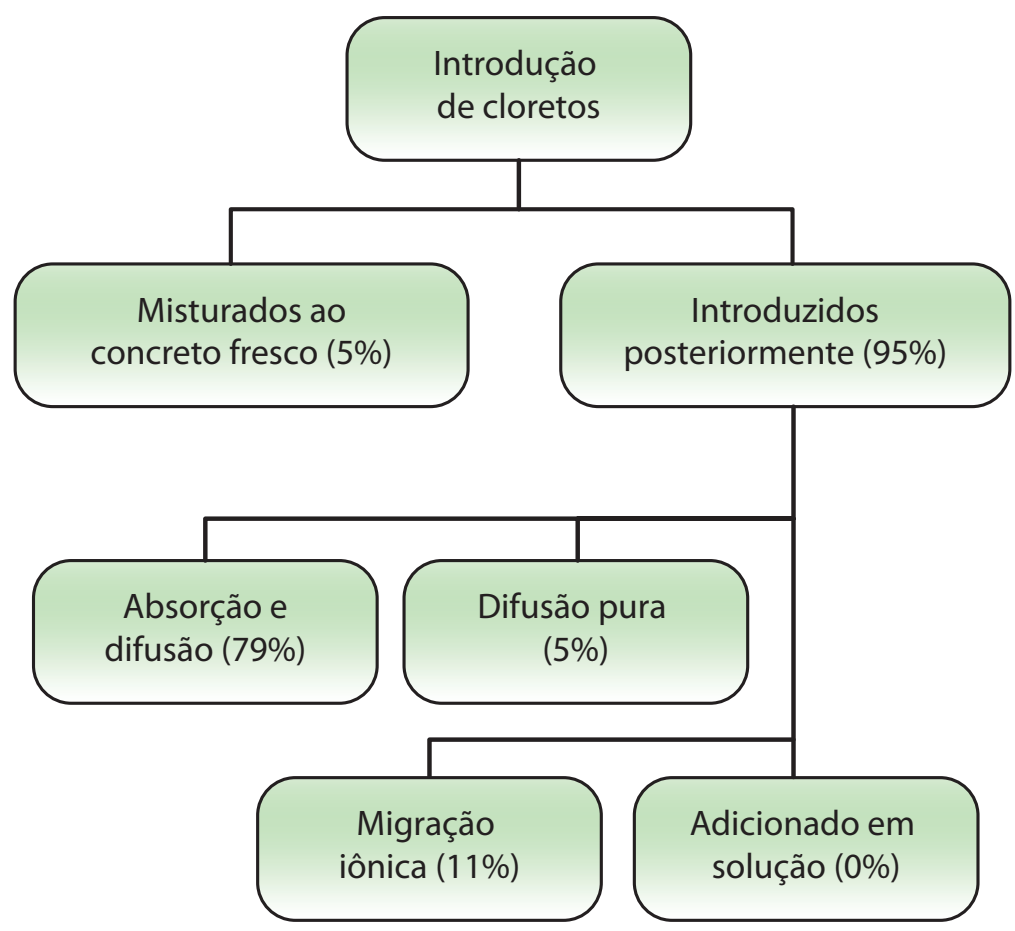

Figura 2. Formas de introdução de cloretos em ensaios acelerados de corrosão - Cenário nacional. Fonte: Ferreira (2015).

Os métodos tradicionalmente empregados pelos pesquisadores envolvem a adição de cloretos à água de amassamento do concreto (ARYA e XU, 1994; GARCIA-ALONSO et al., 2007); a aplicação de um campo elétrico para acelerar a penetraçáo de cloretos no concreto, caracterizando os ensaios baseados na migração iônica (CASTELLOTE et al., 2002; TREJO e PILLAI, 2003), conforme exemplifica a Figura 3; a submissão de concretos a ciclos de secagem e imersão em solução salina, no qual prevalece o mecanismo de transporte por absorção nas camadas mais superficiais e difusão nas camadas internas (MEIRA et al., 2010; SILVA, 2006) e a submissão de concretos à difusão pura através do ensaio de "ponding" (Figura 4) ou à imersão em solução salina (CHIANG e YANG, 2007). No entanto, os resultados obtidos por meio desses métodos carecem de serem confrontados com resultados obtidos a partir de situaçóes reais, de modo a correlacionar os resultados, conforme realizado por Meira et al. (2014). 
(a)

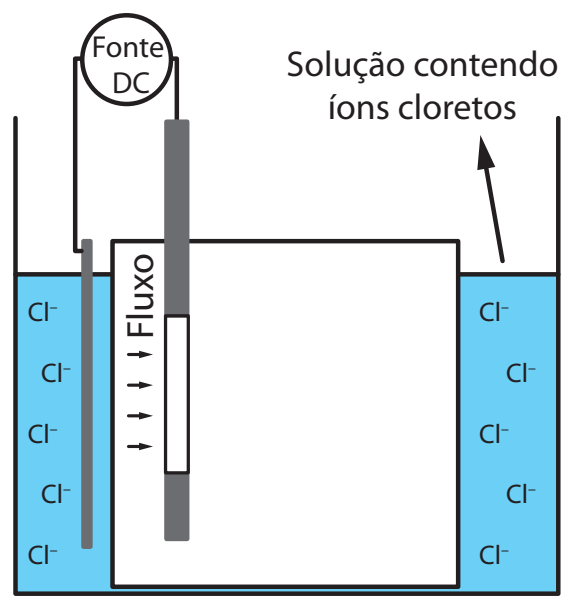

(b)

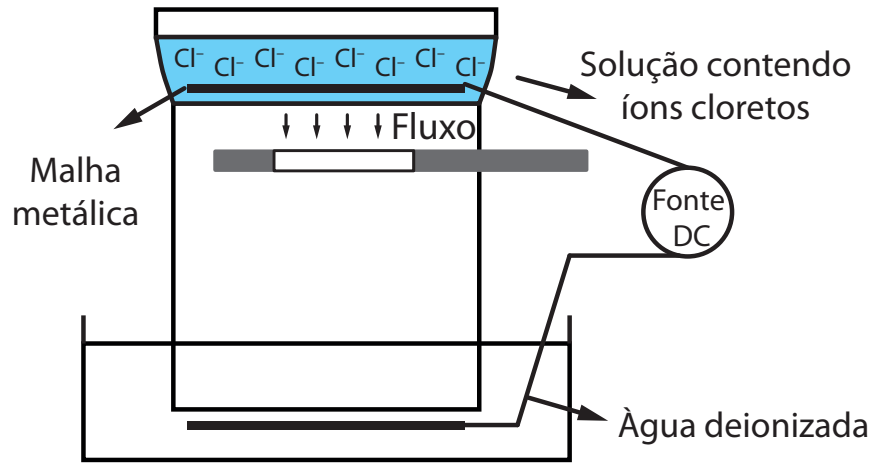

Figura 3. Ensaio de indução da corrosão por migração iônica - configuração com a armadura como um dos pólos conectado (a) e configuração com pólos de conexão independentes da armadura (b). Fontes: Cabrera (1996) e Castellote et al. (2002).

No cenário internacional, o método acelerado mais empregado é a adição salina à massa de concreto fresco, seguido por aqueles que empregam difusão pura, como o "ponding test". No cenário nacional, o método mais empregado é o de imersão e secagem em solução salina, com participação muito superior aos demais métodos.

A variação nos procedimentos de ensaio apresentados pode influenciar no tempo para despassivação, no mecanismo de transporte, no comportamento eletroquímico da barra e no teor crítico de cloretos. A Tabela 1 faz uma breve análise dos principais métodos acelerados empregados para indução do transporte e corrosão por cloretos em concretos armados. 


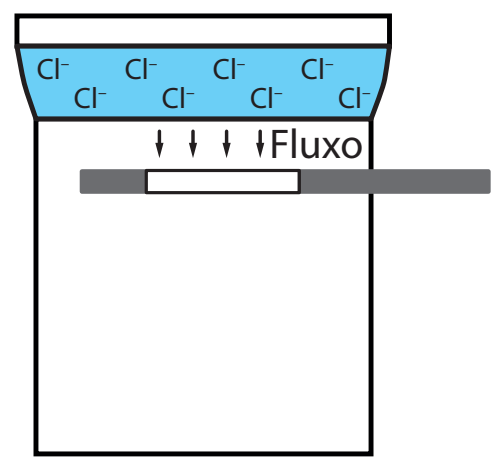

Figura 4. "ponding test" ou ensaio com piscina. Fonte: AASHTO T 259 (1980).

Tabela 1. Características dos métodos de ensaio acelerado empregados na indução da corrosão por cloretos.

\begin{tabular}{|c|c|c|c|c|c|}
\hline \multirow{2}{*}{$\begin{array}{l}\text { Características } \\
\text { analisadas }\end{array}$} & \multicolumn{5}{|c|}{ Tipo de ensaio } \\
\hline & $\begin{array}{l}\text { Adição à } \\
\text { massa }\end{array}$ & $\begin{array}{l}\text { Ciclos de } \\
\text { imersão e } \\
\text { secagem }\end{array}$ & $\begin{array}{l}\text { Migração } \\
\text { iônica }\end{array}$ & $\begin{array}{l}\text { "ponding } \\
\text { test" }\end{array}$ & $\begin{array}{l}\text { Simulação } \\
\text { em } \\
\text { solução }\end{array}$ \\
\hline Tempo de ensaio & $0 \circ$ & - & o & $\bullet$ & 00 \\
\hline $\begin{array}{l}\text { Simplicidade de } \\
\text { procedimento }\end{array}$ & $\bullet \bullet$ & $\bullet$ & ০ & - & $\bullet \bullet$ \\
\hline $\begin{array}{l}\text { Afinidade com a } \\
\text { realidade }\end{array}$ & ०० & $\bullet$ & $\circ$ & • & ०० \\
\hline $\begin{array}{l}\text { Facilidade de } \\
\text { leituras de } \\
\text { concentração de } \\
\text { cloretos }\end{array}$ & $\bullet \bullet$ & - & - & - & $\bullet \bullet$ \\
\hline $\begin{array}{l}\text { Possibilidade de } \\
\text { monitoramento } \\
\text { eletroquímico } \\
\text { durante o ingresso } \\
\text { de cloretos }\end{array}$ & $\begin{array}{l}\text { Não se } \\
\text { aplica }\end{array}$ & $\bullet \bullet$ & ○ & $\bullet \bullet$ & $\bullet \bullet$ \\
\hline $\begin{array}{l}\text { Alterações no } \\
\text { concreto e/ou na } \\
\text { interface com a } \\
\text { armadura com a } \\
\text { aplicação do ensaio }\end{array}$ & $\bullet$ & 00 & $\bullet \bullet$ & ०० & $\bullet$ \\
\hline
\end{tabular}

Legenda: $\bullet$ Muito alto $\bullet$ Alto - Médio $\circ$ Baixo $\circ \circ$ Muito baixo. 


\section{Concretos com Uso de Resíduo Cerâmico}

A confecção de concretos com o uso de resíduos da construção civil (RCC) vem sendo estudada desde o fim da Segunda Guerra Mundial, considerando a sua viabilidade técnico-econômica de cunho sustentável (OLORUNSOGO e PADAYACHEE, 2002; BEKTAS, 2014). Esses estudos envolvem a avaliação das propriedades mecânicas do concreto (LEVY,2001), a viabilidade econômica do seu emprego (VIEIRA e DAL MOLIN, 2004), o processo de hidratação e formação de compostos do cimento com resíduos (TYDLITÁT et al., 2012), o transporte de massa na matriz cimentícia (TOLEDO FILHO et al., 2007) e alguns estudos de durabilidade (OLORUNSOGO e PADAYACHEE, 2002; VAZQUEZ et al., 2013).

A composição dos resíduos da construção civil pode apresentar significativa variabilidade. Contudo, os resíduos oriundos de materiais cerâmicos representam uma grande fatia da composição do RCC, com quantitativos que assumem valores de 26\% em Porto Alegre, 48\% em Maceió, 21\% em Campinas e $14 \%$ em Salvador. Em outros países, essa fatia é de 32\% na Holanda e 35\% em Taiwan (LEITE, 2001; VIEIRA e DAL MOLIN, 2004).

A inserção desses resíduos no concreto pode se dar por meio da substituição dos agregados ou substituição parcial do cimento. A maior parte dos estudos se concentra na substituiçáo de agregados naturais por agregado reciclado de RCC (VIEIRA e DAL MOLIN, 2004; TYDLITÁT et al., 2012). Estudos focados na avaliação de concretos com substituição de cimento por resíduos cerâmicos ainda são poucos (VEJMELKOVÁ et al., 2012).

Considerando a substituição de agregado graúdo por agregado reciclado de RCC, o trabalho de Levy (2001) mostra que a resistência mecânica do concreto não é afetada até a faixa de $20 \%$ de substituição, seguida por quedas drásticas até $100 \%$ de substituição. Nesse contexto, Vázquez et al. (2013) observaram um sutil aumento na resistência à compressão até a faixa de $20 \%$ de substituição, seguida de queda nessa propriedade. Por outro lado, Zong et al. (2014) relatam que a resistência mecânica diminui com a substituição de agregado graúdo natural por agregados reciclados de resíduos de tijolos. Esses autores acrescentam que há uma queda da massa específica do material e um aumento na absorção total.

Levando em consideração a substituição do cimento por resíduo de tijolo moído (RTM), Toledo Filho et al., (2007) e Vejmelková et al. (2012) observaram que a resistência mecânica do material tende a aumentar até uma 
faixa máxima de substituição entre $10 \%$ e $20 \%$ e, em seguida, a resistência diminui consideravelmente.

Com relação à hidratação de pastas com substituição de cimento por RTM, Tydlitát et al. (2012) relatam que o calor de hidratação diminui significativamente com a substituição do cimento por esse tipo de resíduo reciclado, uma vez que o uso desse material retarda a hidratação do $\mathrm{C}_{3} \mathrm{~S}$. Esses autores também concluem que as substituiçóes estudadas têm efeito sobre a hidratação do cimento até o limite de substituição de $20 \%$ e o percentual excedente atua essencialmente na forma de filler.

Considerando o comportamento do coeficiente de difusão em matrizes com a incorporação de resíduos cerâmicos reciclados, Zong et al. (2014), estudando concretos com a incorporação de agregados de resíduos cerâmicos, obtiveram um aumento de pouca expressão nesse parâmetro, até a faixa de $30 \%$ de substituição, seguido por aumentos significativos até o nível de substituição de 50\%. Por outro lado, Vejmelkova et al. (2012), estudando concretos com a adição de RTM em substituição ao cimento, apesar de não terem avaliado diretamente o transporte de cloretos, obtiveram um bom desempenho de concretos com níveis de substituição até 20\%, quer seja em relação à resistência mecânica, quer seja em relação a ensaios relacionados à durabilidade, como absorção de água.

Sobre a alcalinidade de concretos com a incorporação RTM, percebe-se que há uma redução gradativa no $\mathrm{pH}$ da matriz com a adição do resíduo. Vejmelková et al. (2012) observaram que os concretos de referência apresentam valores de $\mathrm{pH}$ da água de lixiviação da ordem de 12 após 60 dias de imersão em água destilada, enquanto que concretos com substituição de 60\% do cimento por RTM apresentaram pH da água de lixiviação da ordem de 11, demonstrando a redução de alcalinidade em função da incorporação do RTM.

Assim como os concretos convencionais, os concretos com a incorporação de resíduos cerâmicos reciclados também estão sujeitos a processos de degradação decorrentes da ação ambiental. A ação dos cloretos representa uma importante fonte de degradação das estruturas de concreto armado devido à corrosão das armaduras. Ensaios que avaliam o transporte de cloretos na matriz cimentícia e a despassivação de armaduras, quer sejam com a aplicação de campo elétrico, quer não, buscam obter parâmetros que quantifiquem esta maior ou menor habilidade de transporte e resistência à corrosão e são amplamente utilizados como instrumentos de comparação entre distintas mesclas de concreto ou na avaliação do período de iniciação da corrosão. 
Sabendo que o período de iniciação da corrosão se finaliza com a despassivação da armadura (TUUTTI, 1982), a quantidade de cloretos necessária para desencadear esse processo (teor crítico de cloretos) depende das características da matriz cimentícia, em especial, do $\mathrm{pH}$ da solução dos poros do concreto (HAUSMANN, 1967). Nesse sentido, o uso de adiçóes minerais costuma contribuir para uma redução do teor crítico, em função do consumo de hidróxidos nas reaçóes pozolânicas (MEIRA et al., 2014). No entanto, ainda há a carência de estudos sobre o tema para matrizes que empregam materiais reciclados de resíduos cerâmicos.

\section{Estudo Experimental de Concretos com RTM com Foco na Corrosão de Armaduras}

No presente capítulo, avalia-se o processo de indução da corrosão por cloretos em concretos armados com a incorporação de RTM por meio dos ensaios acelerados de imersão e secagem e migração iônica. Para tanto, consideraram-se dosagens com três teores de RTM e concentrou-se a análise no tempo de ensaio, na resposta em relação ao comportamento eletroquímico das armaduras, bem como no teor crítico de cloretos. Os detalhes dos procedimentos adotados são descritos, de forma simplificada, a seguir.

\subsection{Materiais Empregados}

O resíduo utilizado nesta pesquisa é originário da indústria de cerâmica vermelha, obtido a partir do descarte de tijolos de uma indústria cerâmica que abastece o mercado da Paraíba. Após a seleção, o material foi moído em moinho de bolas até atingir uma superfície específica próxima a do cimento. A Tabela 2 mostra as características químicas e físicas do RTM, bem como do cimento CPV empregado.

Seguindo as recomendaçôes da NBR 5752 (ABNT, 2012), o índice de atividade pozolânica (IAP) do RTM empregado foi de $86 \%$. Durante todo o andamento de caracterização dos materiais, confecção dos corpos de prova (CPs) e exposição ao ambiente agressivo, o resíduo empregado foi considerado pozolânico ${ }^{1}$.

1. Com a atualização da NBR 5752 em 2014, o limite mínimo do IAP passou para $90 \%$, o que não seria atendido pelo RTM empregado. 
Tabela 2. Características químicas e físicas do RTM e do cimento empregados.

\begin{tabular}{|c|c|c|c|c|c|}
\hline \multicolumn{2}{|c|}{$\begin{array}{l}\text { Características } \\
\text { analisadas }\end{array}$} & \multirow{2}{*}{$\begin{array}{l}\text { RTM } \\
0,4\end{array}$} & \multirow{2}{*}{$\begin{array}{l}\text { Limite } \\
(\text { NBR 12653/12) }\end{array}$} & \multirow{2}{*}{$\begin{array}{l}\text { Cimento } \\
\text { CPV } \\
-\end{array}$} & \multirow[t]{2}{*}{$\begin{array}{l}\text { Limite } \\
\text { (NBR 5733/91) }\end{array}$} \\
\hline Composição & $\mathrm{Na}_{2} \mathrm{O}$ & & & & \\
\hline & $\mathrm{MgO}$ & 1,1 & - & 0,4 & $\leq 6,5$ \\
\hline & $\mathrm{Al}_{2} \mathrm{O}_{3}$ & 16,2 & - & 2,6 & \\
\hline & $\mathrm{SiO}_{2}$ & 51,9 & - & 10,9 & \\
\hline & $\mathrm{P}_{2} \mathrm{O}_{5}$ & 0,2 & - & - & \\
\hline & $\mathrm{SO}_{3}$ & 1,2 & - & 4,1 & $\leq 3,5$ \\
\hline & $\mathrm{K}_{2} \mathrm{O}$ & 4,8 & - & 0,6 & \\
\hline & $\mathrm{CaO}$ & 3,5 & - & 73,3 & \\
\hline & $\mathrm{Fe}_{2} \mathrm{O}_{3}$ & 16,4 & & 5,0 & \\
\hline & $\mathrm{SrO}$ & 0,1 & - & 0,1 & \\
\hline & $\mathrm{ZrO}_{2}$ & 0,1 & - & - & \\
\hline & $\mathrm{TiO}_{2}$ & 2,0 & - & 0,4 & \\
\hline & $\mathrm{V}_{2} \mathrm{O}_{5}$ & 0,2 & - & 0,1 & \\
\hline & $\mathrm{BaO}$ & 0,3 & - & - & \\
\hline & $\mathrm{MnO}$ & 0,1 & - & 0,1 & \\
\hline \multicolumn{2}{|c|}{$\begin{array}{l}\text { Perda ao fogo (\%) - } \\
\text { NBR 5743/77 }\end{array}$} & 1,5 & - & 2,4 & $\leq 4,5$ \\
\hline \multicolumn{2}{|c|}{$\begin{array}{l}\text { Blaine }\left(\mathrm{cm}^{2} / \mathrm{g}\right)- \\
\text { NBR NM } 76 / 98\end{array}$} & 5.080 & - & 3.820 & $\geq 3.000$ \\
\hline \multicolumn{2}{|c|}{$\begin{array}{l}\text { Massa específica } \\
\left(\mathrm{g} / \mathrm{cm}^{3}\right) \text { - NBR NM 23/01 }\end{array}$} & 2,62 & - & 3,15 & - \\
\hline
\end{tabular}

As dosagens empregadas estáo descritas na Tabela 3, assim como as características físicas e mecânicas das dosagens. 
Tabela 3. Características físicas das dosagens.

\begin{tabular}{|c|c|c|c|c|c|}
\hline \multirow{2}{*}{\multicolumn{3}{|c|}{$\begin{array}{l}\text { Características Analisadas } \\
\text { Traços em massa }\end{array}$}} & \multicolumn{3}{|c|}{ Traços (Cimento: RTM: Areia: Brita: a/ag²) } \\
\hline & & & \multirow{2}{*}{$\begin{array}{l}\text { 1:0:1,86: } \\
2,25: 0,55\end{array}$} & \multirow{2}{*}{$\begin{array}{l}0,9: 0,1: 1,86: \\
2,25: 0,55\end{array}$} & \multirow{2}{*}{$\begin{array}{l}0,7: 0,3: 1,86 \\
2,25: 0,55\end{array}$} \\
\hline & & & & & \\
\hline \multicolumn{3}{|c|}{ Abatimento $(\mathrm{mm})$ - NBR NM 67/98 } & 220 & 210 & 190 \\
\hline \multicolumn{3}{|c|}{ Consumo de aglomerante $\left(\mathrm{kg} / \mathrm{m}^{3}\right)$} & 414,3 & 414,3 & 414,3 \\
\hline \multicolumn{3}{|c|}{ Consumo de cimento CPV $\left(\mathrm{kg} / \mathrm{m}^{3}\right)$} & 414,3 & 372,9 & 290,0 \\
\hline \multirow[t]{6}{*}{$\begin{array}{l}\text { Absorção total } \\
\text { - NBR 9778/05 }\end{array}$} & \multirow[t]{3}{*}{$\begin{array}{l}28 \\
\text { dias }\end{array}$} & $\begin{array}{l}\text { M. esp. } \\
\left(\mathrm{g} / \mathrm{cm}^{3}\right)\end{array}$ & 2,58 & 2,58 & 2,57 \\
\hline & & $\begin{array}{l}\text { Ind. de } \\
\text { vazios (\%) }\end{array}$ & 15,10 & 15,35 & 15,39 \\
\hline & & $\begin{array}{l}\text { Absorção } \\
(\%)\end{array}$ & 6,87 & 7,01 & 7,07 \\
\hline & \multirow[t]{3}{*}{$\begin{array}{l}90 \\
\text { dias }\end{array}$} & $\begin{array}{l}\text { M. esp. } \\
\left(\mathrm{g} / \mathrm{cm}^{3}\right)\end{array}$ & 2,58 & 2,59 & 2,57 \\
\hline & & $\begin{array}{l}\text { Ind. de } \\
\text { vazios (\%) }\end{array}$ & 15,05 & 15,30 & 15,39 \\
\hline & & $\begin{array}{l}\text { Absorção } \\
(\%)\end{array}$ & 6,87 & 6,98 & 7,07 \\
\hline Resistência & \multicolumn{2}{|c|}{14 dias } & 41,0 & 33,1 & 29,4 \\
\hline Mecânica & \multicolumn{2}{|c|}{28 dias } & 47,1 & 35,9 & 32,9 \\
\hline $\begin{array}{l}(\mathrm{MPa})-\mathrm{NBR} \\
5738 / 03\end{array}$ & \multicolumn{2}{|c|}{90 dias } & 52,2 & 47,2 & 44,6 \\
\hline
\end{tabular}

$\mathrm{Na}$ preparação dos corpos de prova, empregaram-se barras de aço CA 50, as quais foram previamente limpas por meio de decapagem química, segundo procedimento ASTM G1 (2011). Para o emprego dessas barras, delimitouse uma longitude intermediária de exposição de $3 \mathrm{~cm}$, conforme detalha a Figura 5. A cura úmida realizada foi de 28 dias.

Ao final do período de cura, das seis faces dos corpos de prova, quatro foram pintadas com resina epóxi para garantir um fluxo unidirecional de cloretos. Seis barras (três corpos de prova) foram empregadas para cada condição de ensaio.

2. a/ag = relação água/aglomerante . 


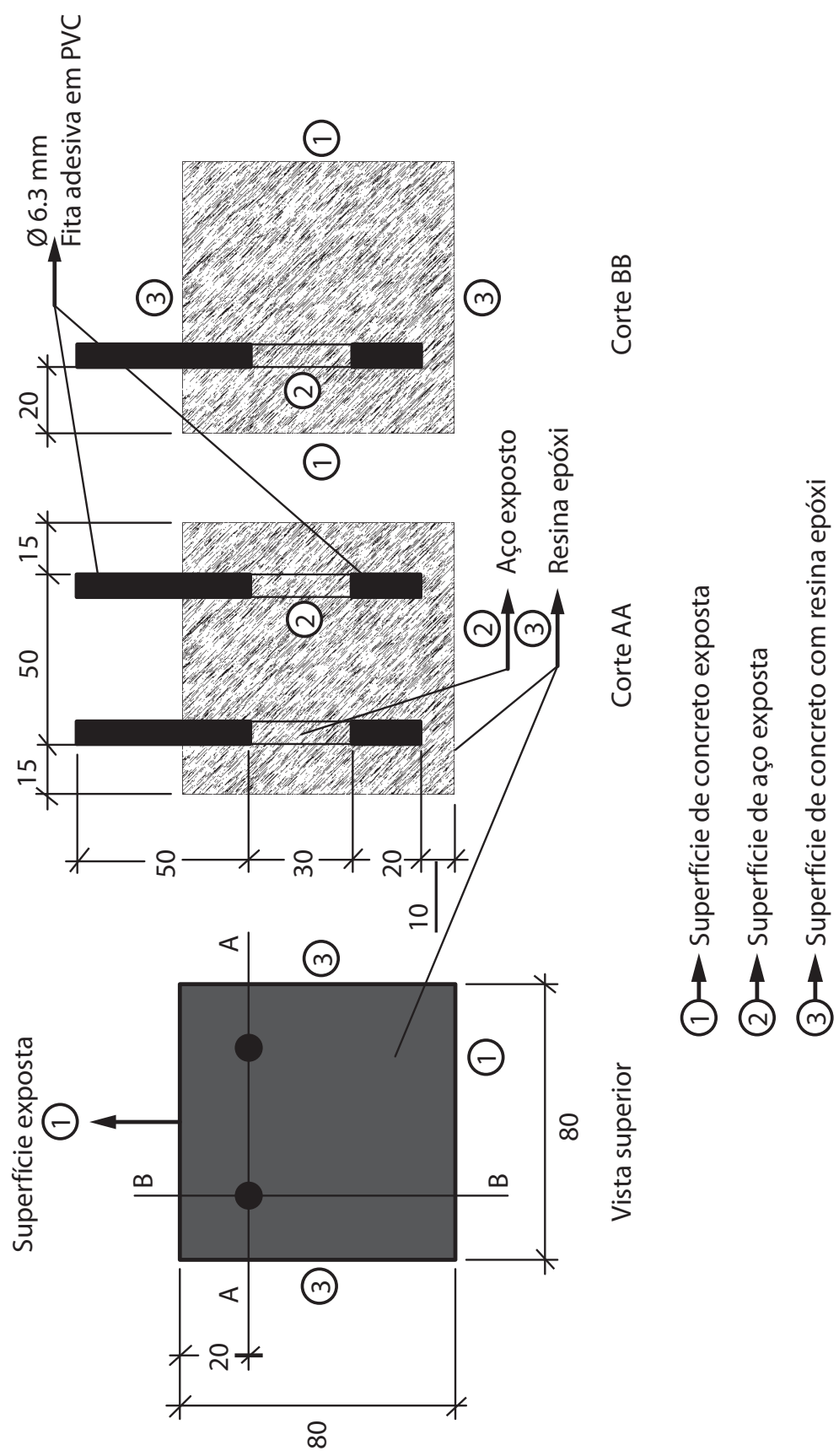

Figura 5. Características geométricas dos corpos de prova (medidas em mm). 


\subsection{Ensaios Acelerados para Indução da Corrosão}

Nos ciclos de imersão e secagem, empregou-se secagem em estufa a $45^{\circ} \mathrm{C}$ por quatro dias e imersão em solução de cloreto de sódio $1 \mathrm{M}$ por 3 dias, com renovação da solução a cada dois ciclos (Figura 6).
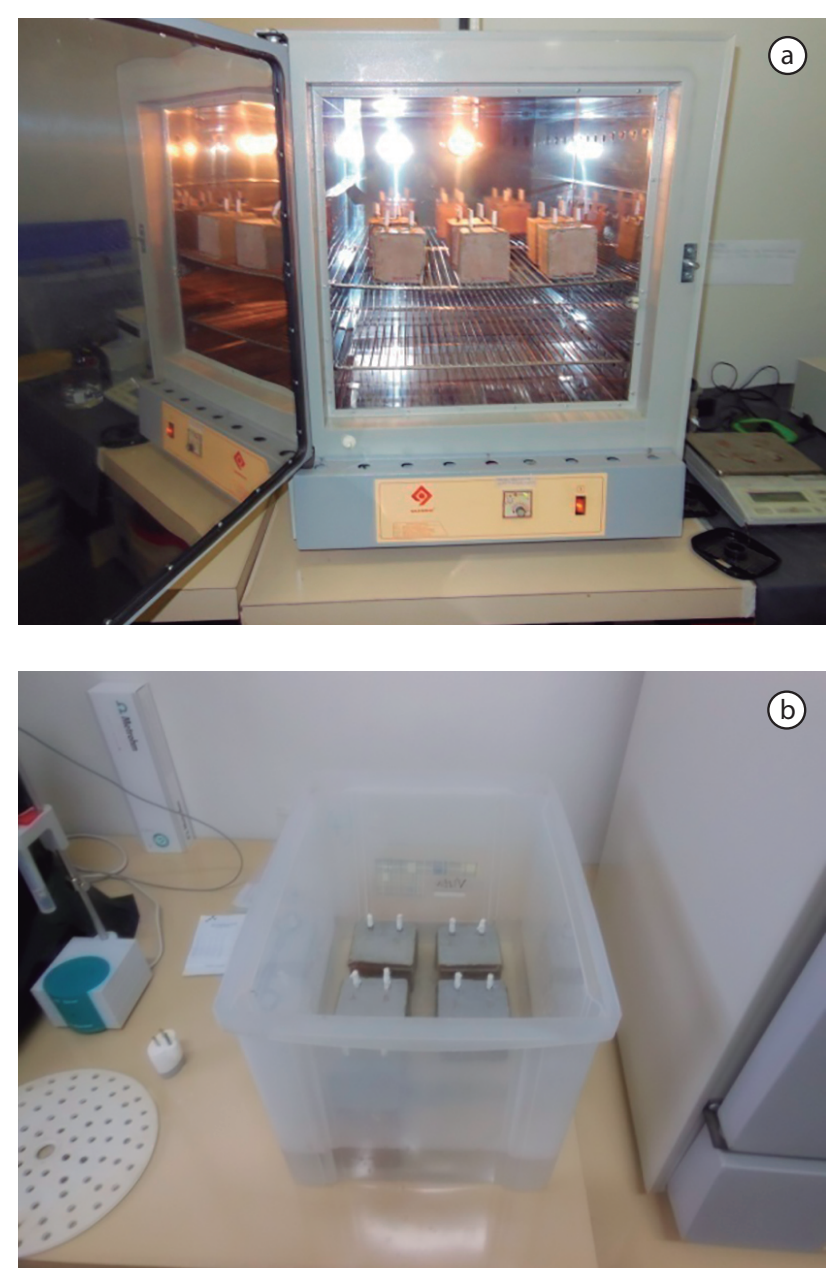

Figura 6. Configuração de ensaio por imersão e secagem - secagem em estufa (a) e imersão em solução salina (b).

Nos ensaios de migração iônica, empregou-se um campo elétrico de 12 V e a mesma solução salina de cloreto de sódio $1 \mathrm{M}$ (Figura 7). Os corpos de prova foram previamente saturados em água deionizada e o campo elétrico foi aplicado em intervalos que compreendiam cinco horas em funcionamento 
e dezenove horas em repouso, para minimizar o efeito de polarização da armadura nas medidas eletroquímicas realizadas em seguida.
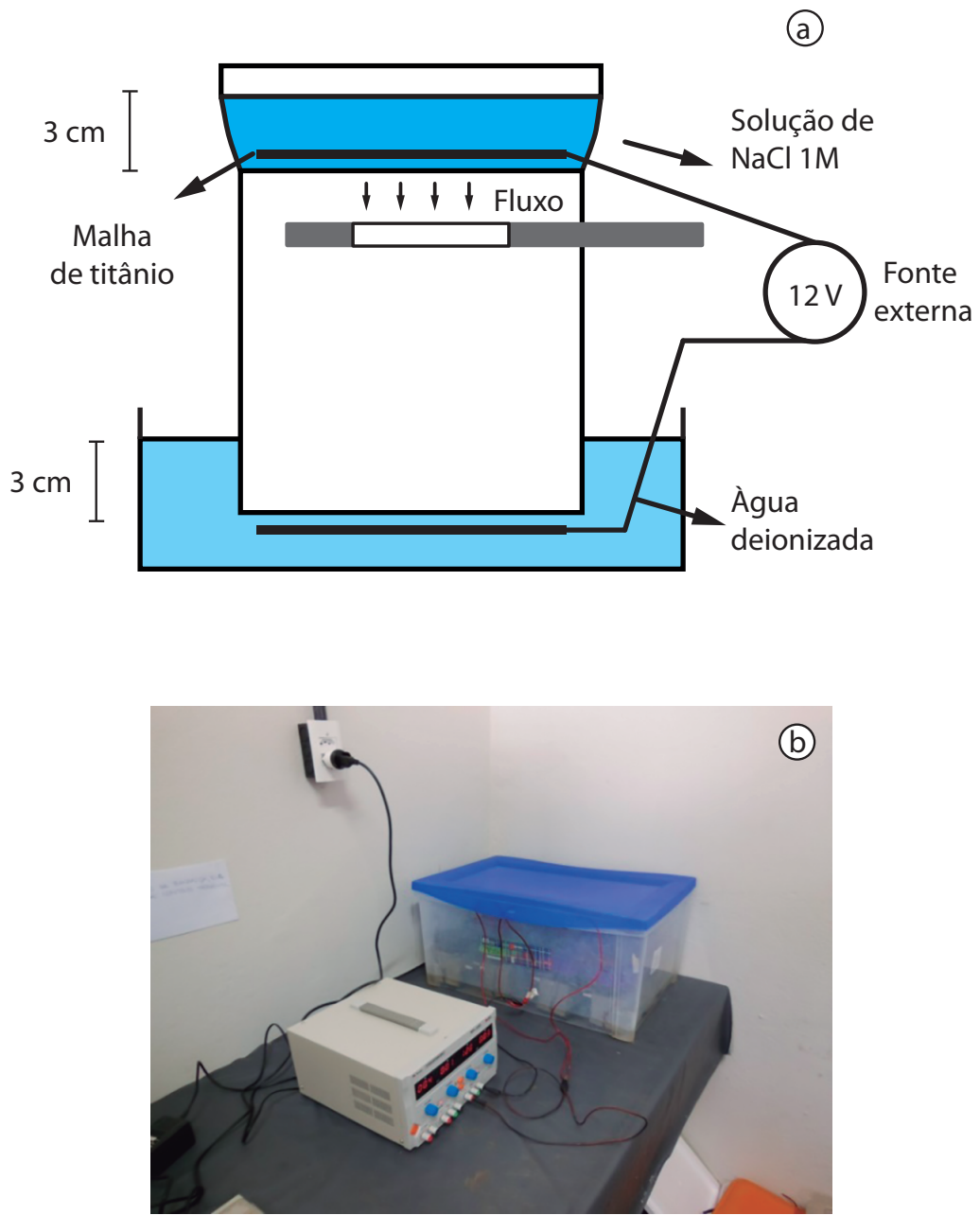

Figura 7. Configuração do ensaio de migração iônica - desenho esquemático (a), realização do ensaio (b).

\subsection{Avaliação da Alcalinidade da Matriz Cimentícia}

A avaliação da alcalinidade das matrizes estudadas se baseou no método proposto por Oliveira e Agopyan (2000), o qual consiste na lixiviação de 
compostos alcalinos da matriz cimentícia quando posta em contato com água deiozidada durante certo período de tempo.

No presente caso, foram confeccionadas pastas de cimento com a adição, em massa, de RTM nas proporçôes de 0, 10, 20 e 30\%. Após um período de cura semelhante ao empregado nos corpos de prova, esse material foi triturado e colocado em contato com água deionizada por um período de 90 dias, em ambiente inerte. Durante esse período, medidas de $\mathrm{pH}$ dessa água de lixiviação foram realizadas nas idades de $0,7,28$ e 90 dias.

\subsection{Monitoramento Eletroquímico}

O monitoramento eletroquímico, realizado em ambos os ensaios, baseouse em medidas de potencial de corrosão em circuito aberto e na técnica eletroquímica de resistência à polarização com compensação da queda ôhmica, para obtenção da densidade de corrente instantânea de corrosão.

O equipamento empregado nas leituras foi um ponteciostato de bancada, com um eletrodo de referência de $\mathrm{Cu} \mid \mathrm{CuSO}_{4}$ (ESC) e um contra-eletrodo de aço inoxidável, mantendo-se todo o conjunto envolto por uma gaiola de Faraday para evitar interferências externas (Figura 8).
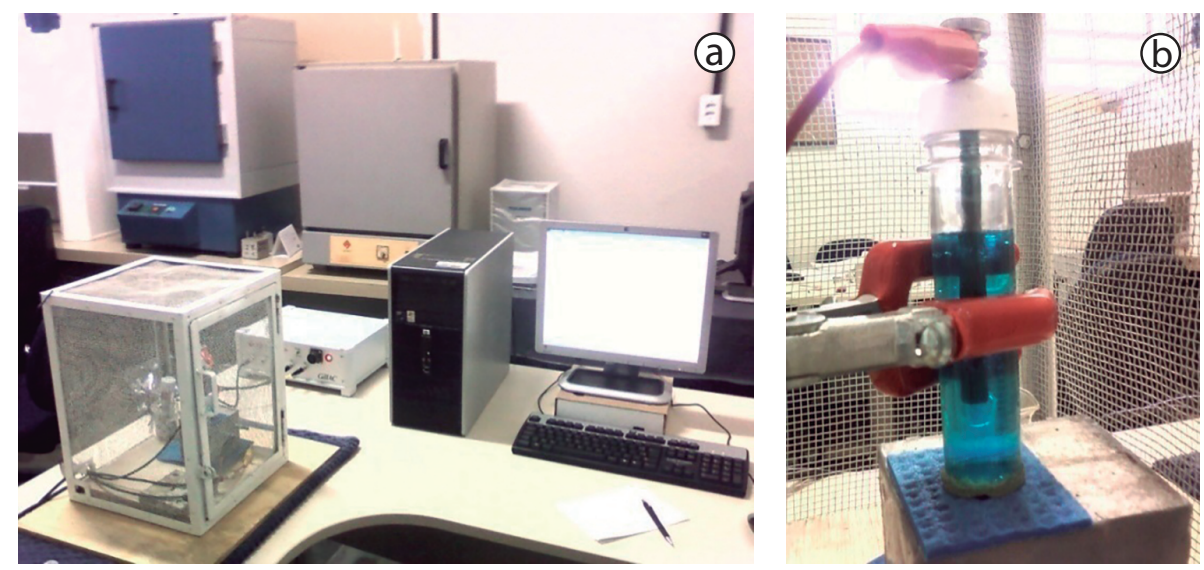

Figura 8. Arranjo para as medidas de resistência de polarização - vista geral (a) e detalhe (b).

O critério adotado para a identificação da despassivação da armadura foi o seguinte: duas medidas consecutivas com potencial de corrosão mais eletronegativo que $-350 \mathrm{mV}$ (ESC) e densidade de corrente de corrosão 
superior a $0,1 \mu \mathrm{A} / \mathrm{cm}^{2}$, seguindo recomendações da ASTM C876 (2009) e de Cigna et al. (1997).

\section{Resultados e Análises}

\subsection{Alcalinidade das Matrizes}

A alcalinidade da matriz cimentícia está diretamente ligada à formação e estabilidade da película passivadora no interior do concreto. Na fase líquida, tal alcalinidade é garantida pela presença dos hidróxidos de sódio $(\mathrm{NaOH})$, de potássio $(\mathrm{KOH})$ e, de forma complementar, da portlandita (hidróxido de cálcio) (ANDRADE e PAGE, 1986). Os concretos estudados apresentaram uma redução de alcalinidade com o incremento do teor de RTM (Figura 9), explicado pelas reaçóes pozolânicas que consomem parte dos hidróxidos da matriz cimentícia, em especial o hidróxido de cálcio.

A Figura 9 apresenta resultados até 90 dias e mostra que as diferenças de pH da água de lixiviação, em comparação com a mistura de referência, podem alcançar o patamar de 0,6 para 30\% de RTM, o que significa uma variação na concentração de $\mathrm{OH}^{-}$de mais de 3,5 vezes.

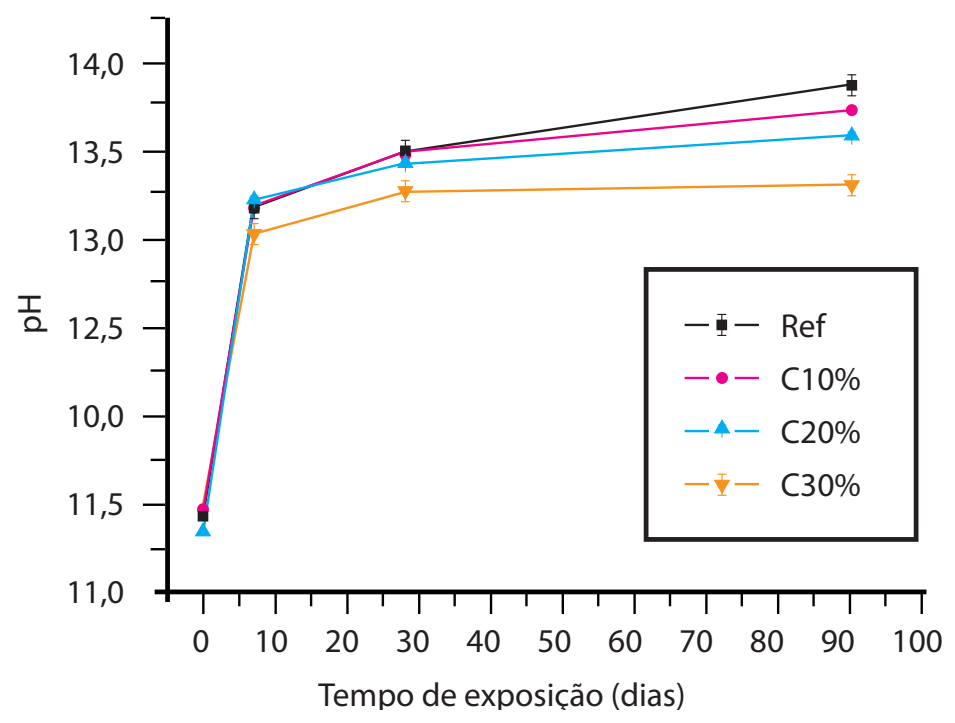

Figura 9. pH da água de lixiviação com o tempo de exposição. 


\subsection{Período de Iniciação da Corrosão}

Como era de se esperar, os ensaios de migração iônica, por contarem com a aplicação de um campo elétrico, apresentaram menor período de iniciação da corrosão. Por outro lado, a incorporação de RTM também reduziu o período de iniciação da corrosão. As Figuras 10 e 11 mostram o comportamento eletroquímico dos materiais estudados e, por meio das medidas de potencial de corrosão e densidade de corrente de corrosão, mostram essa influência.

As faixas indicadas nos gráficos de potencial de corrosão e densidade de corrente de corrosão se baseiam nos referenciais sugeridos pela ASTM C876 (2009) e Cigna et al. (1997), quando se referem à probabilidade de corrosão e ao risco de corrosão, respectivamente.
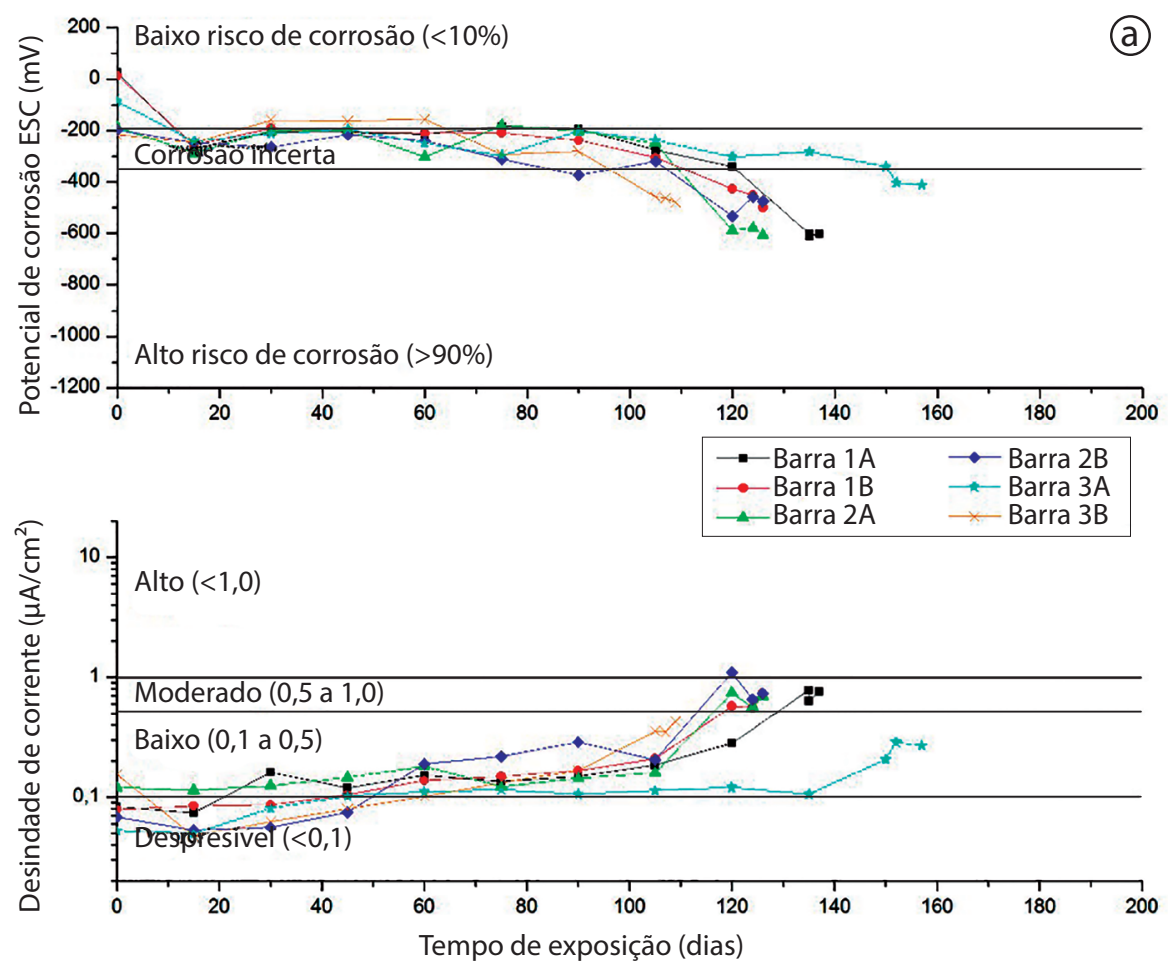

Figura 10. Evolução temporal do potencial de corrosão e densidade de corrente de corrosão nos ensaios de imersão e secagem - Traço de referência (a), Traço com $10 \%$ de RTM (b), Traço com 30\% de RTM (c). 

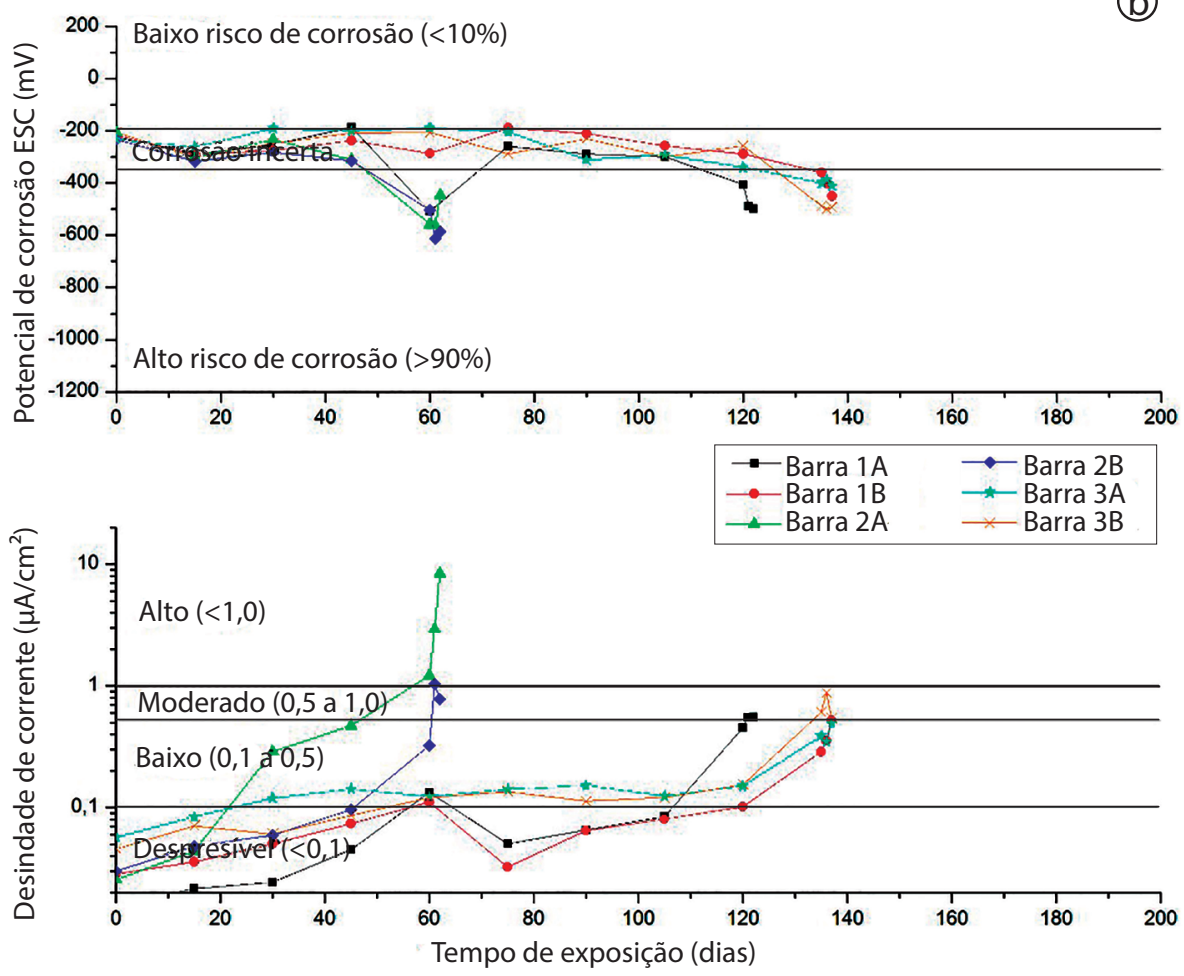

Figura 10. Continuação. 


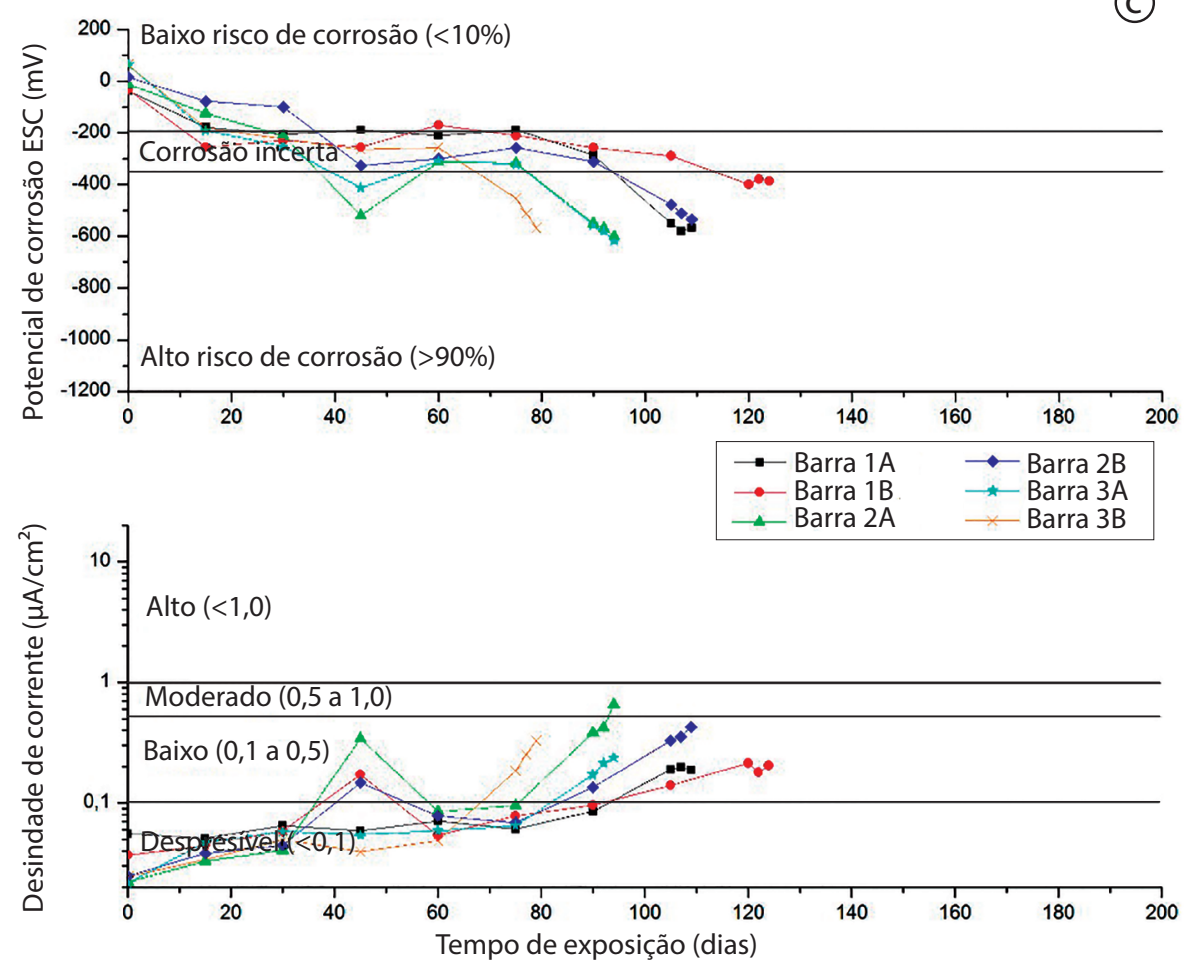

Figura 10. Continuação.

Tendo como referência a Figura 10, observa-se que o tempo médio de despassivação e o seu desvio padrão foram de $98 \pm 16$ dias para concretos com $30 \%$ de RTM, $108 \pm 38$ dias para concretos com 10\% de RTM e $128 \pm 16$ dias para o concreto de referência. 
(a)
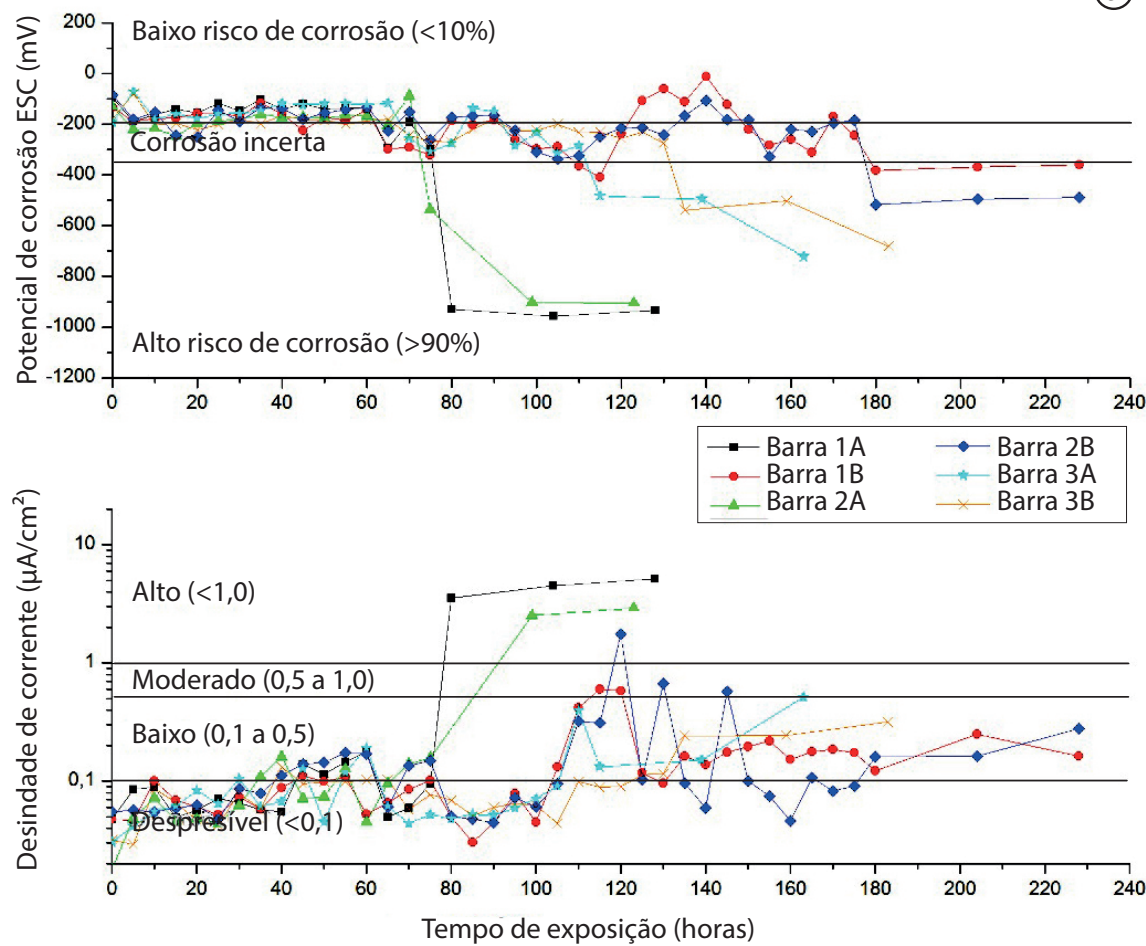

Figura 11. Evolução temporal do potencial de corrosão e densidade de corrente de corrosão nos ensaios de eletromigração - Traço de referência (a), Traço com $10 \%$ de RTM (b), Traço com 30\%de RTM (c). 


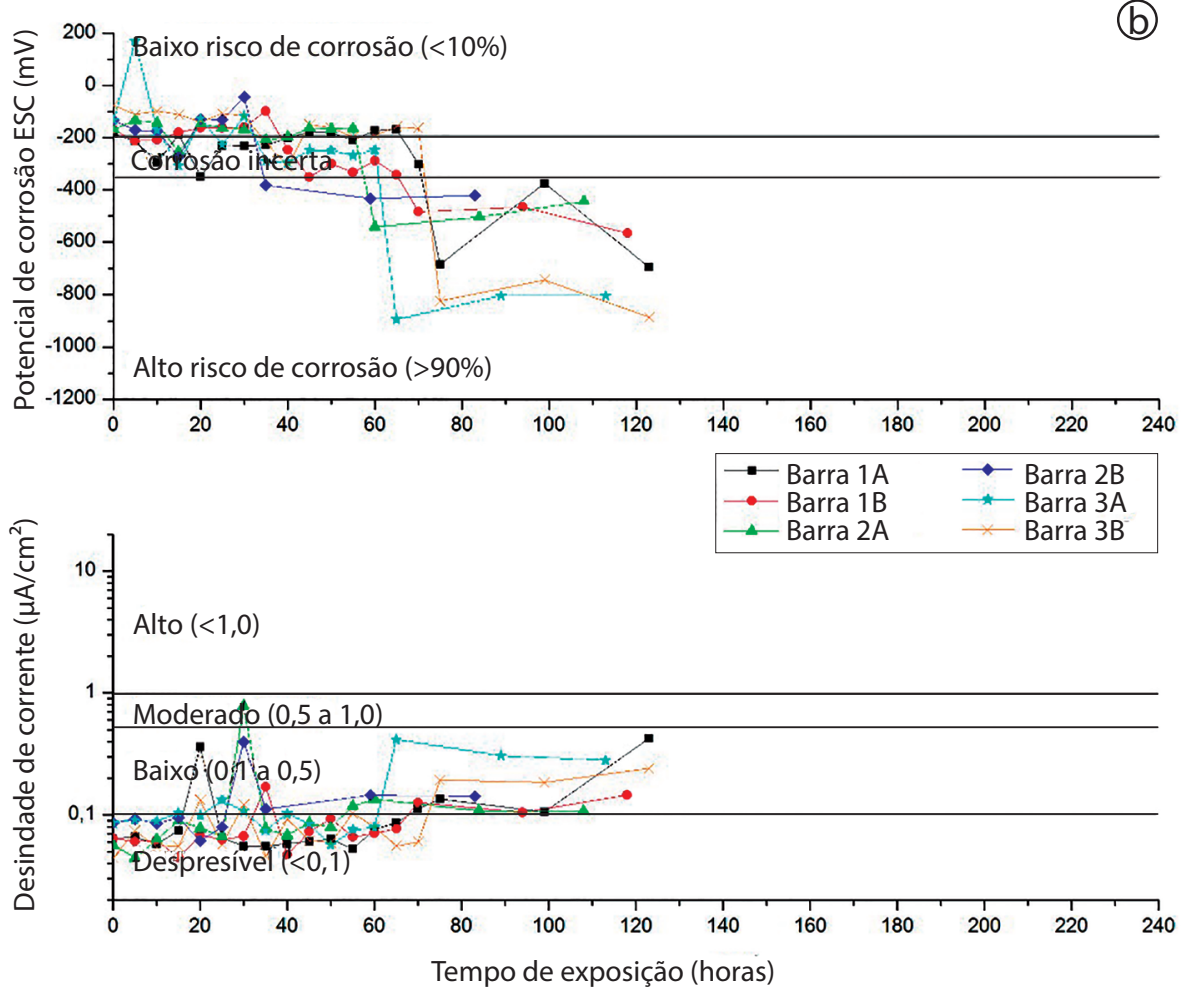

Figura 11. Continuação. 


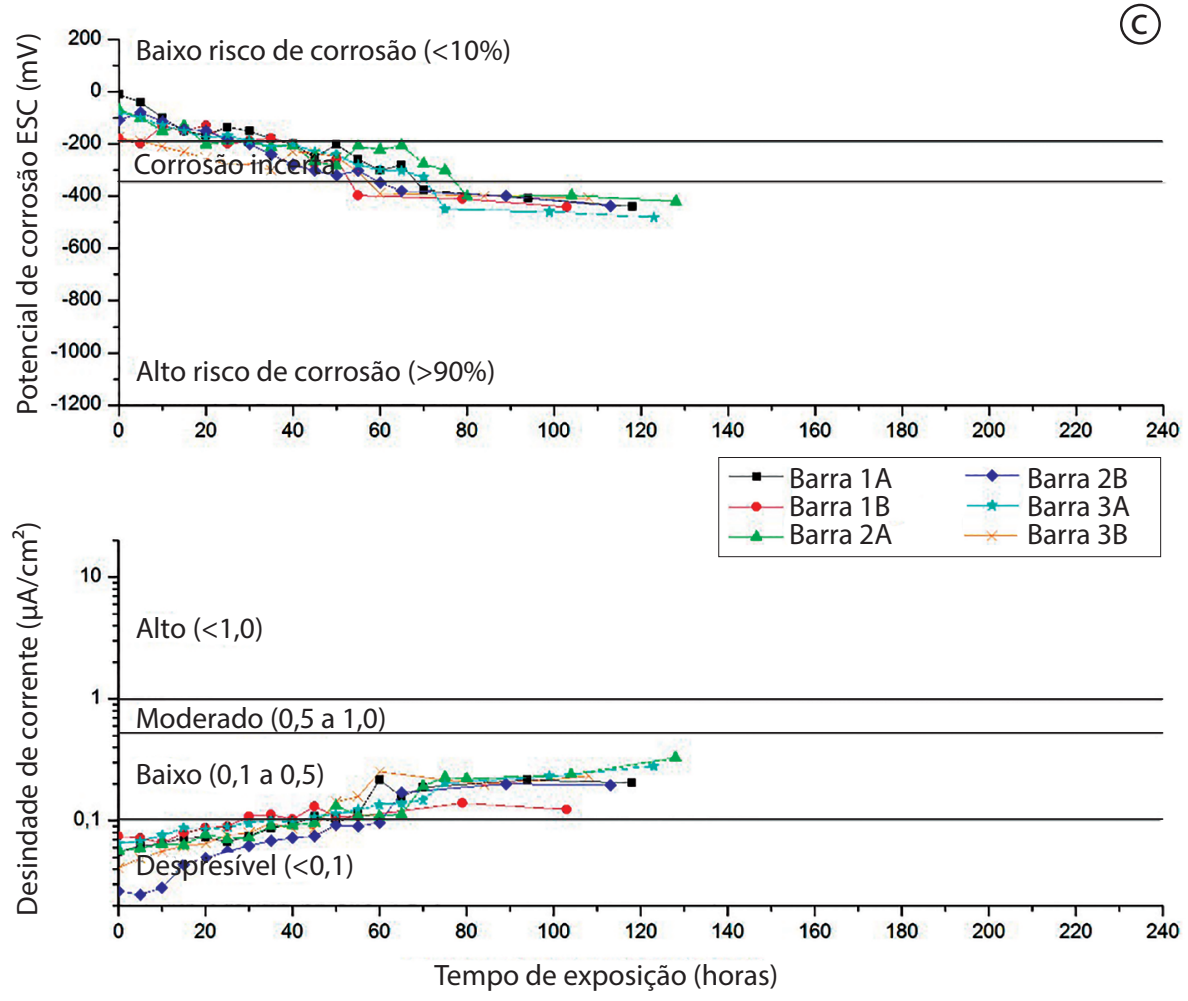

Figura 11. Continuação.

Tendo como referência a Figura 11, observa-se que o tempo médio de despassivação e o seu desvio padrão foram de 63,33 \pm 15,1 horas para concretos com $10 \%$ de RTM, de 67,5 \pm 9,4 horas para concretos com $30 \%$ de RTM e de $127,5 \pm$ 46,3 horas para o concreto de referência.

De modo geral, percebe-se que a substituição de cimento por RTM reduz o tempo de exposição dos espécimes até a detecção do início do processo corrosivo, o que pode ser explicado pela redução de alcalinidade das matrizes com RTM, com impacto sobre o teor crítico de cloretos. O leve aumento da porosidade nas misturas com RTM, com possível impacto sobre a velocidade de transporte de cloretos, não se confirmou por meio dos perfis de cloretos (FERREIRA, 2015). 


\subsection{Teor Crítico de Cloretos}

Os resultados de teores críticos de cloretos foram obtidos a partir de ajustes da Segunda Lei de Fick aos perfis de cloretos reescalonados, segundo procedimento descrito por Andrade e Alonso (1997), logo após a identificação da despassivação da armadura. Considerou-se o teor crítico o valor de concentração em que a curva ajustada toca a superfície da barra (Figura 12). Considerando o reescalonamento dos perfis, a profundidade do pite é a menor distância entre a superfície do concreto e o pite formado, e o período de iniciação da corrosão corresponde ao tempo de exposição ao ambiente deletério até a detecção da despassivação. Esse procedimento foi empregado tanto para os teores de cloretos totais como para os teores de cloretos livres. Após a obtenção dos valores de teores críticos, adicionalmente, foi empregada a técnica estatística de Chauvenet para análise dos dados espúrios, o que permitiu o emprego de dados mais consistentes e representativos da amostra.

A Figura 13 mostra os resultados médios e desvios padróes dos teores críticos para cloretos livres e totais. Observa-se um decréscimo no teor crítico com a incorporação de RTM, para todas as combinaçóes propostas. Esse comportamento é explicado pela redução na alcalinidade do concreto com a substituição de cimento por RTM e este é motivado pela redução no consumo de cimento em cada traço (Tabela 2) e pelas reaçôes pozolânicas entre o cimento e o RTM (MEIRA et al., 2014; FERREIRA, 2015). Menor alcalinidade da matriz significa uma formaçáo menos eficiente da película de passivação e menor tolerância à presença de cloretos, representada pela relação $\left[\mathrm{Cl}^{-}\right] /\left[\mathrm{OH}^{-}\right]$, conforme observado por Hausmann (1967). 

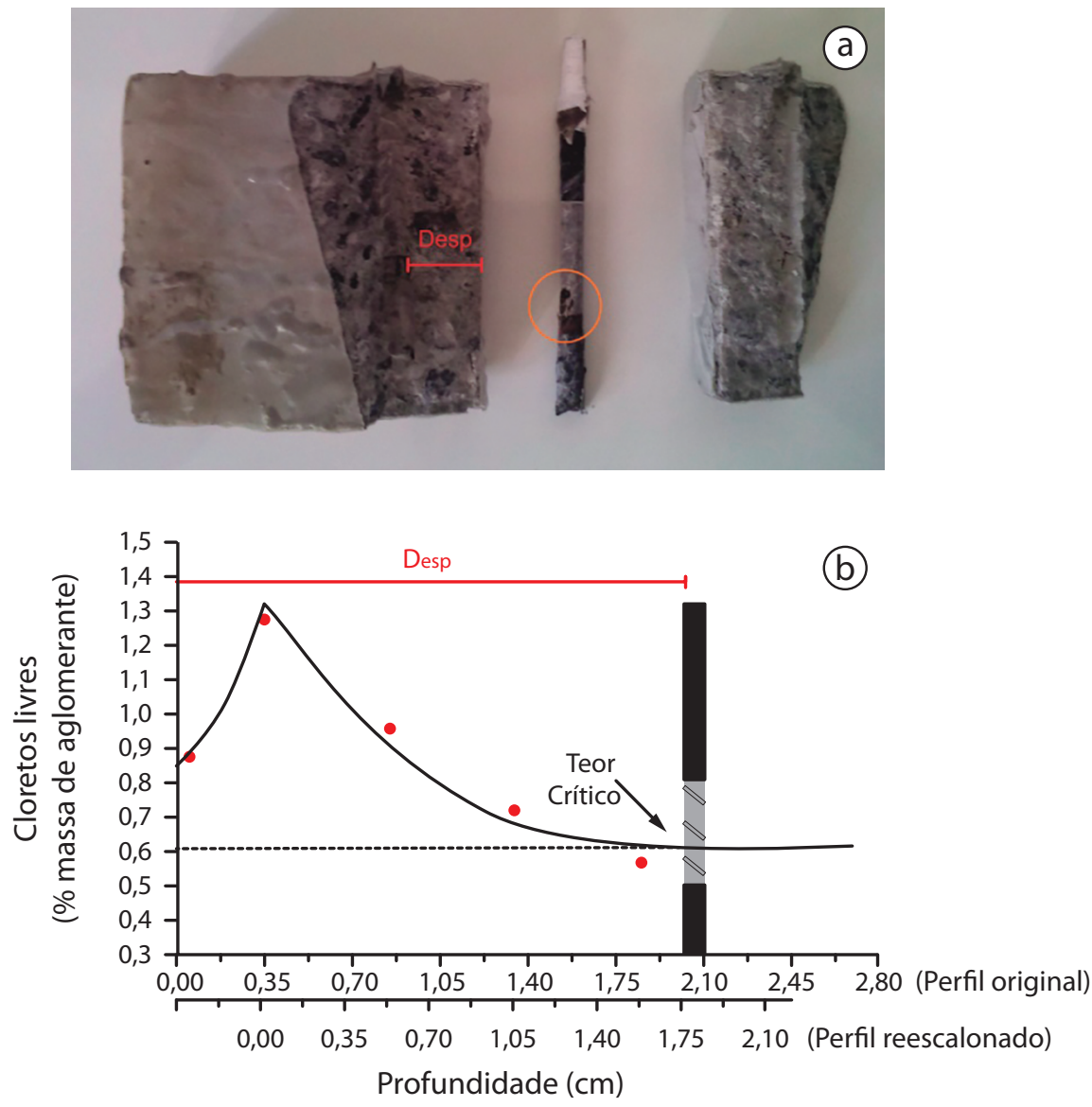

— Ajustes a 2a Lei de Fick

- Pontos titulados

Figura 12. Detecção do pite de corrosão (a) e identificação do teor crítico de cloretos (b). 


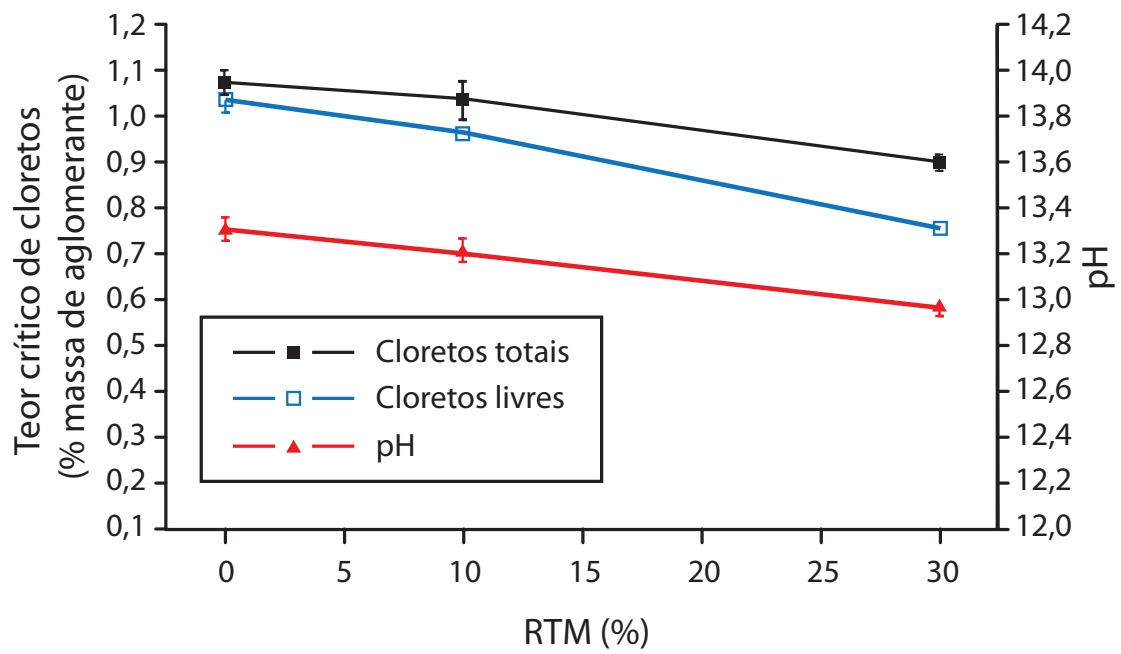

Figura 13. Teor crítico de cloretos livres e totais em função do percentual de RTM - imersão e secagem.

Considerando os ensaios de migração iônica, observa-se, por meio da Figura 14, que, para esse ensaio, a substituição de cimento por RTM também reduz progressivamente os teores críticos de cloretos livres e totais, conforme observado nos ensaios de imersão e secagem.

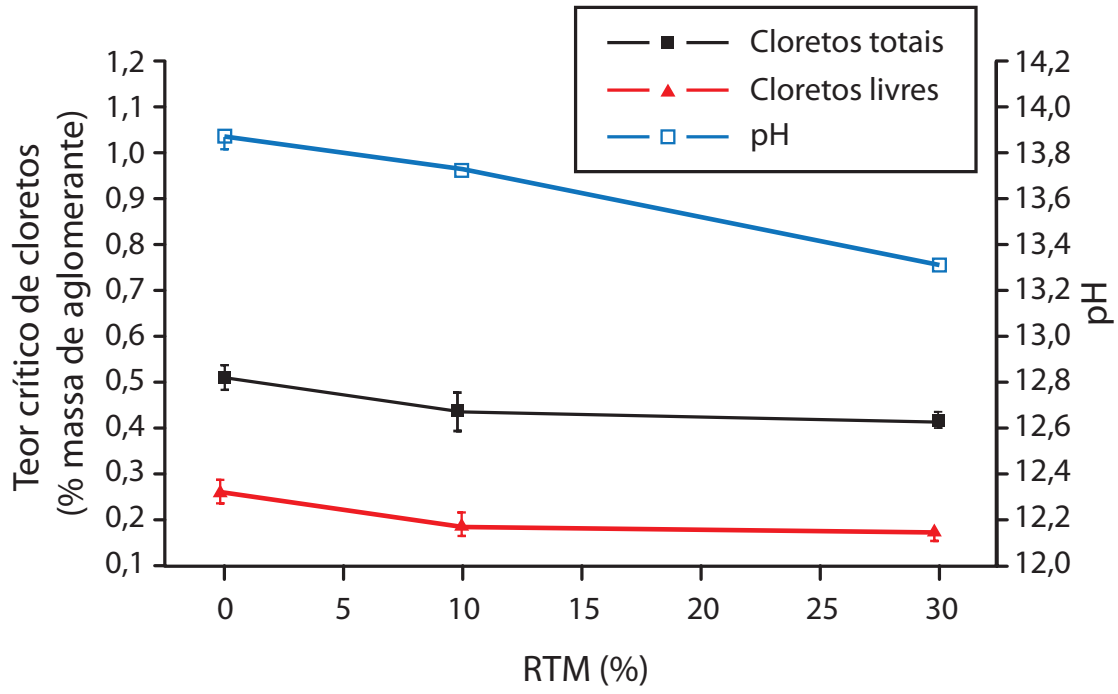

Figura 14. Teor crítico de cloretos livres e totais em função do percentual de RTM - migração iônica. 


\subsection{Comparação Entre os Métodos Acelerados de Indução da Corrosão}

\subsubsection{Período de Iniciação da Corrosão e Monitoramento Eletroquímico}

Os tempos para despassivação da armadura foram bastante diferenciados. Concretos armados submetidos ao ensaio de imersão e secagem demoraram cerca de até 150 dias para atingir a ativação da armadura, enquanto os concretos submetidos ao ensaio de migração permaneceram em ensaio por, no máximo, 180 horas, o que representa uma diferença significativa. Segundo Angst et al. (2009), a maior vantagem do ensaio de migração é a rapidez. Contudo, existem algumas inconveniências, como se comenta a seguir.

A aplicação do campo elétrico através do concreto armado gera polarização na armadura, esse fenômeno interfere nas leituras de potencial de corrosão e densidade de corrente. No entanto, tal efeito é reversível (AUSTIN et al., 2009; CASTELLOTE et al., 2002). Um tempo mínimo de despolarização de 48 horas foi requerido para que as medidas de potencial de corrosão e densidade de corrente de corrosão se apresentassem com menor influência desse efeito.

\subsubsection{Teor Crítico de Cloretos}

A partir da análise dos resultados de teor crítico de cloretos livres e totais, percebe-se a influência da variável dosagem, tanto para os ensaios de imersão e secagem, quanto para os ensaios de migração. Observa-se que quanto menor a substituição de cimento por resíduo de tijolo moído, maiores são os valores de teor crítico de cloretos livres e totais em ambos os ensaios.

Em comparaçáo com os resultados apresentados na literatura, observase que os valores de teor crítico de cloretos estáo em consonância com outros estudos, considerando ensaios acelerados semelhantes. No entanto, comparando os resultados deste trabalho com os valores obtidos de espécimes submetidos à exposiçáo natural, percebe-se um aumento nos teores críticos de cloretos para corpos de prova submetidos a ciclos de imersão e uma redução de valores para corpos de prova submetidos ao ensaio de migração iônica. 
O incremento nos valores do teor crítico de cloretos livres e totais dos espécimes submetidos ao ensaio de imersão e secagem se explica em função de alguns aspectos: um aumento no grau de hidratação desses corpos de prova em função dos semi ciclos de imersão e um consequente refino da porosidade do material, com impacto no comportamento da película de passivação (MEIRA et al., 2014); uma menor disponibilidade de oxigênio em camadas próximas da armadura, em virtude dos espécimes estarem com os poros saturados em boa parte do tempo (ANGST et al., 2009) e aos curtos ciclos de passivação e repassivação até a consolidação do início do processo corrosivo, colaborando para a penetração de mais cloretos (MEIRA et al., 2014).

A redução dos teores críticos de cloretos para os ensaios de migração iônica, em comparação aos obtidos em exposição natural, pode ser explicado por alteraçóes de equilíbrio químico, devido à ação do campo elétrico (CASTELLOTE et al., 2002; ANGST et al., 2009; TREJO et. al., 2009). No entanto, essas diferenças não se apresentaram de forma acentuada, como pode ser observado no trabalho de Meira (2004) e na Tabela 4.

Tabela 4. Limites mínimos e máximos para teores críticos de cloretos livres e totais, com nível de confiança de $99 \%$.

\begin{tabular}{llllll}
\hline \multirow{2}{*}{$\begin{array}{l}\text { Tipo de } \\
\text { ensaio }\end{array}$} & $\begin{array}{l}\text { Tipo de } \\
\text { concreto }\end{array}$ & \multicolumn{2}{l}{$\begin{array}{l}\text { Cloretos livres (\% massa } \\
\text { de aglomerante) }\end{array}$} & \multicolumn{2}{l}{$\begin{array}{l}\text { Cloretos totais (\% massa } \\
\text { de aglomerante) }\end{array}$} \\
\cline { 2 - 6 } & & Mínimo & Máximo & Mínimo & Máximo \\
\hline Imersão e & Referência & 0,7203 & 0,7819 & 1,0418 & 1,1018 \\
\cline { 2 - 6 } secagem & $10 \%$ de RTM & 0,6732 & 0,7354 & 0,9877 & 1,0848 \\
\cline { 2 - 6 } & $30 \%$ de RTM & 0,5584 & 0,6106 & 0,8768 & 0,9182 \\
\hline Migração & Referência & 0,2399 & 0,2821 & 0,4889 & 0,5311 \\
\cline { 2 - 6 } iônica & $10 \%$ de RTM & 0,1785 & 0,1995 & 0,4295 & 0,4505 \\
\cline { 2 - 6 } & $30 \%$ de RTM & 0,1605 & 0,1815 & 0,3939 & 0,4361 \\
\hline
\end{tabular}

\section{Considerações Finais}

Os ensaios com a aplicação de campo elétrico têm a vantagem de encurtar o período de ensaio. Contudo, a perturbação provocada pela presença do campo elétrico traz inconvenientes em relação ao monitoramento eletroquímico, bem como em relação ao teor crítico de cloretos. Isso faz com que o mesmo deva ser 
aplicado com cuidado, quando o objetivo passar por uma análise quantitativa. Nesse contexto, os concretos submetidos ao ensaio de imersão e secagem, apesar de demandarem mais tempo de ensaio, têm a vantagem de envolverem mecanismos de transporte semelhantes aos observados em situaçóes reais. Em ambos os casos, deve-se pensar em calibrar os resultados de teor crítico de cloretos com resultados de exposição natural, de forma semelhante ao que propóe Meira et al. (2014).

Considerando o impacto da substituição do cimento por RTM no teor crítico de cloretos, há uma tendência de redução dos teores críticos com o aumento do nível de substituição, o que se observa de forma mais pronunciada nos ensaios de migração iônica.

Partindo do pressuposto que ensaios de imersão e secagem têm mais afinidade com a realidade, já que envolvem mecanismos de transporte semelhantes ao caso de exposição natural, conclui-se que a substituição de cimento por RTM é tecnicamente viável, em ambientes favoráveis à corrosão por cloretos, até um nível de substituição de 10\%, havendo uma forte tendência de melhorar o seu desempenho com o tempo, dado o avanço das reaçóes pozolânicas.

\section{Referências Bibliográficas}

AMERICAN ASSSOCIATION OF STATE HIGHWAY AND TRANSORTATION OFFICIALS. AASHTO T 259: Standard method of test for resistance of concrete to chloride ion penetration. Washington, 1980.

AMERICAN SOCIETY FOR TESTING AND MATERIALS. ASTM C-876. Standard test for half-cell potentials of uncoated reinforcing steel in concrete. Anual Book of ASTM Standards. Philadelphia, 2009.

AMERICAN SOCIETY FOR TESTING AND MATERIALS. ASTM G1. Standard Practice for Preparing, Cleaning, and Evaluation Corrosion Test Specimens. Anual Book of ASTM Standards. Philadelphia, 2011.

ANDRADE, C.; ALONSO, M. C. Modelling of skin effects on diffusion process in concrete. In: Nilsson, L. O.; Ollivier, J. P., editors. International RILEM workshop on chloride penetration into concrete, 1995, Paris. Proceedings..., Paris: RILEM; 1997. p.182-194.

ANDRADE, C.; PAGE, C. L. Pore solution chemistry and corrosion in hydrated cement systems containing chloride salts: a study of cation specific effects. British Corrosion Journal. v. 21, p. 49-53, 1986.

ANGST, U. M.; VENNESLAND, Ø. Critical chloride content in reinforced concrete State of the art. Concrete Repair, Rehabilitation and Retrofitting II. Taylor \& Francis Group, London, p. 311-317, 2009. 
ANGST, U. M.; ELSENER, B.; LARSEN, K.; VENNESLAND, Ø. Critical chloride content in reinforced concrete - A review. Cement and Concrete Research. v. 39, n. 12, p. 1122-1138, 2009.

ARYA, C.; XU, Y. Effect of cement type on chloride binding and corrosion of steel in concrete. Cement and Concrete Research. v. 25, n. 4, p. 893-902, nov. 1994.

ASSOCIAÇÃO BRASILEIRA DE NORMAS TÉCNICAS. NBR 5743: Cimento Portland - Determinação de perda ao fogo. Rio de Janeiro, 1977.

ASSOCIAÇÃO BRASILEIRA DE NORMAS TÉCNICAS. NBR 5733: Cimento Portland de alta resistência inicial. Rio de Janeiro, 1991.

ASSOCIAÇÃO BRASILEIRA DE NORMAS TÉCNICAS. NM 67: Concreto Determinação da consistência pelo abatimento do tronco de cone. Rio de Janeiro, 1998.

ASSOCIAÇÃO BRASILEIRA DE NORMAS TÉCNICAS. NM 76: Cimento Portland Determinação da finura pelo método de permeabilidade ao ar (Método de Blaine). Rio de Janeiro, 1998.

ASSOCIAÇÃO BRASILEIRA DE NORMAS TÉCNICAS. NM 23: Cimento Portland e outros materiais em pó - Determinação da massa específica. Rio de Janeiro, 2001.

ASSOCIAÇÃO BRASILEIRA DE NORMAS TÉCNICAS. NBR 5738: Concreto Procedimento para moldagem e cura de corpos de prova. Rio de Janeiro, 2003.

ASSOCIAÇÃO BRASILEIRA DE NORMAS TÉCNICAS. NBR 9778: Argamassa e concreto endurecidos - Determinação da absorção de água, índice de vazios e massa específica. Rio de Janeiro, 2005.

ASSOCIAÇÃO BRASILEIRA DE NORMAS TÉCNICAS. NBR 5752: Materiais pozolânicos — Determinação do índice de desempenho com cimento Portland aos 28 dias. Rio de Janeiro, 2012.

ASSOCIAÇÃO BRASILEIRA DE NORMAS TÉCNICAS. NBR 12653: Materiais pozolânicos - Requisitos. Rio de Janeiro, 2012.

AUSTIN, S. A.; LYONS, R.; ING, M. Electrochemical behaviour of steel reinforced concrete during accelerated corrosion testing. Corrosion. v. 60, n. 2, p. 203-212, 2009.

BEKTAS, F. Alkali reactivity of crushed clay brick aggregate. Construction and Building Materials. v. 52, p. 79-85, 2014.

CABRERA, J. G. Deterioration of Concrete Due to Reinforcement Steel Corrosion. Cement and Concrete Composites. v. 18, p. 47-59, 1996.

CASTEllote, M.; ANDRADE, C.; ALONSO, C. Accelerated simultaneous determination of the chloride depassivation threshold and of the non-stationary diffusion coefficient values. Corrosion Science. v. 44, p. 2409-2424, feb. 2002.

CHIANG, C. T.; YANG, C. C. Relation between the diffusion characteristic of concrete from salt ponding test and accelerated chloride migration test. Materials Chemistry and Physics. v. 106 p. 240-246, 2007. 
CIGNA, R.; ANDRADE, C.; NÜRNBERGER, U.; POLDER, R.; WEYDERT, E.; SEITZ, E. Corrosion and protection of metals in contact with concrete. COST Action 509 - Final Report. European Community: Luxembourg, 1997.

FERREIRA, P. R. R. Análise da indução da corrosão por cloretos em concretos armados com adição de resíduo de tijolo moído a partir de ensaios acelerados. 2015. 195f. Dissertação (Mestrado em Engenharia Civil) - Centro de Tecnologia e Geociências. Pós-graduação em Engenharia Civil da Universidade Federal de Pernambuco, Recife, 2015.

GARCIA-ALONSO, M. C.; SALTA, M. et al. Corrosion behaviour of new stainless steels reinforcing bars embedded in concrete. Cement and Concrete Research. v. 37, p. 14631471 , june 2007.

HAUSMANN, D. A. Steel corrosion in concrete: how does it occur? Materials Protection, p. 19-23, 1967.

LEITE, M. B. Avaliação de propriedades mecânicas de concretos produzidos com agregados reciclados de resíduos de construção e demolição. 2001. 270 f. Tese (Doutorado) - Escola de Engenharia, Curso de Pós-Graduação em Engenharia Civil da Universidade Federal do Rio Grande do Sul, Porto Alegre, 2001.

LEVY, S. M.; Contribuição ao estudo da durabilidade de concretos produzidos com resíduos de concreto e alvenaria. 2001. p.199 tese (Doutorado) - Escola Politécnica da Universidade de São Paulo. Universidade de São Paulo, São Paulo, 2001.

MEIRA, G. R. Agressividade por cloretos em zona de atmosfera marinha frente ao problema da corrosão em estruturas de concreto armado. 2004, 369 f. Tese (Doutorado em Engenharia) Departamento de Engenharia Civil, Universidade Federal de Santa Catarina, Santa Catarina, 2004.

MEIRA, G. R.; ANDRADE, C.; PADARATZ, I. J.; ALONSO, M. C.; BORBA Jr., J. C. Durability of concrete structures in marine atmosphere zones - The use of chloride deposition rate on the wet candle as an environmental indicator. Cement and Concrete Composites. v. 27, p. 667-676, 2010.

MEIRA, G. R.; ANDRADE, C.; VILAR, E. O.; NERY, K. D. Analysis of chloride threshold from laboratory and field experiments in marine atmosphere zone. Construction and Building Materials. v. 55, p. 289-298, 2014.

OLIVEIRA, C. T. A; AGOPYAN, V. Estudo da água do poro de pasta de cimento de escoria pelo método de água de equilíbrio. Boletim técnico da Escola politécnica da USP. BT/ PCC/259. São Paulo, 2000.

OLORUNSOGO, F. T.; PADAYACHEE, N. Performance of recycled aggregate concrete monitored by durability indexes. Cement and Concrete Research. v. 32, p. 179-185, 2002.

SILVA, F. G. Estudo de concretos de alto desempen ho frente à ação de cloretos. Tese (Doutorado em Ciência e Engenharia dos Materiais) - Escola Politécnica, Universidade de São Paulo, São Carlos, 2006. 
TOLEDO FILHO, R. D.; GONÇALVES, J. P.; AMERICANO, B. B.; FAIRBAIRN, E. M .R. Potential for use of crushed waste calcined-clay brick as a supplementary cementitious material in Brazil. Cement and Concrete Research. v. 39, p. 1357-1365, 2007.

TREJO, D.; PILLAI, R. G. Accelerated Chloride Threshold Testing: Part I - ASTM A 615 and A 706 Reinforcement. ACI Materials Journal, v. 100, n. 6, p. 519-527. dec. 2003.

TREJO, D.; HALMEN, C.; REINSCHMIDT, K. Corrosion performance tests for reinforcing steel in concrete: technical report. SL 0-4825-1. Texas Transportation Institute, Inc. p. 7-33, 2009.

TUUTTI, K. Corrosion of steel in concrete. Sweden: CBI, 1982. 468 p.

TYDLITAT, V.; ZAKOUTSKY, J.; VOLFOVA, P.; CERNY, R. Hydration heat development in blended cements containing fine-ground ceramics. Thermochimica Acta. v. 543, p. 125-129, 2012.

VÁZQUEZ, E; BARRA, M.; APONTE, D.; JIMÉNEZ, C.; VALLS, S. Improvement of durability of concrete with recycled aggregates in chloride exposed environment. Constrution and Building Materials, nov. 2013. Disponível em: <http://dx.doi. org/10.1016/j.conbuildmat.2013.11.028>. Acesso em: 13 mar. 2014.

VEJMELKOVA, E.; KEPPERT,M.; ROVNANIKOVA, P.; ONDRACEK,M.; KERŠNER, Z.; CERNY, R. Properties of high performance concrete containing fine-ground ceramics as supplementary cementitious material. Cement and Concrete Composites. v. 34, p. 55-61, 2012.

VIEIRA, G. L.; DAL MOLIN, D. C. C. Viabilidade técnica da utilização de concretos com agregados reciclados de resíduos de construção e demolição. Ambiente Construído. v. 4, n. 4, p. 47-63, out./dez. 2004.

ZONG, L.; FEI, Z.; ZHANGA, S. Permeability of recycled aggregate concrete containing fly ash and clay brick waste. Journal of Cleaner Production. feb.2014.Disponível em: <http://dx.doi.org/10.1016/j.jclepro.2014.02.040>. Acesso em: 23 mar. 2014. 